\title{
"Bunchems" to Increase Fine Motor Skill of Child with Mental Retardation and Global Developmental Delay
}

\author{
Claudya S. Souisa ${ }^{1}$, Ajeng Ayu Widiastuti ${ }^{2}$ \\ \{claudyasouisa@yahoo.com ${ }^{1}$, ajeng.widiastuti@uksw.edu ${ }^{2}$ \} \\ Magister of Science Psychology, Universitas Kristen Satya Wacana ${ }^{1}$, \\ Early Childhood Education Teacher Training Program, Universitas Kristen Satya Wacana ${ }^{2}$
}

\begin{abstract}
The aim of this study is to increase the fine motor skills of a child diagnosed with mental retardation and global developmental delay. Child with both this diagnosed has difficulty to develop her fine motor skills. This subject is 7 years old in Kristha Pertiwi Homeschooling, Semarang Regency. This study is single case design research by using Applied Behavior Analysis (ABA) therapy which accepted for modifying behavior through bunchems. We provide fine motor activity through the process of grasping, grazing, and scooping objects. The result showed that therapeutic activity using bunchems occurs motor process to improve fine motor skills so that child is able to perform better motor activity to increase her independence, especially in writing and carrying objects.
\end{abstract}

Keywords: bunchems, mental retardation, fine motor, global developmental delay, behavior modification

\section{Introduction}

Motor learning has an important role in all areas of development [1]. Fine motor skills generally refer to the small movements of the hands, wrists, fingers, feet, toes, lips, and tongue [2]. Fine motor development begins with strengthening and refining the muscles of the whole arm [3]. At five years old, most children have maturated in develop fine motors such as drawing, cut, paste, and trace shapes [2].

Developmental delay is a significant child's lag in aspects, such as cognitive, behavioral, emotional, or social development. Sometimes this term is used for mental retardation, which is not a delay in developmental but rather a permanent limitation. If there is a delay in fine motor adaptive development combined with delays in other developmental domains, the doctor will consider whether the child is visually impaired or mentally handicapped [4].

Mental retardation have a significant limitation in intellectual functioning and adaptive behavior in social and practical adaptive skills that appear before 18 years old [5]. This disability have a great impact on some activity at schools such as writing and reading. Children with mental retardation have a deficit in severe intellectual and in motor development [6][7].

Based on some results of the previous study, children with mental retardation have delays in motor skills [8][9]. The poor motor performance in children with mental retardation 
related to the impaired of intellectual functioning [10][11][12]. Children with mental retardation may not be able to use knowledge to control their responses because they had difficulty to identify and focus on critical stimuli [1].

Bunchems are creation toys with colorful little balls that stick to each other. Each ball has many thorns, but it is not sharp. Bunchems are commonly used for constructive play. However, its highly flexible use is able for other activities. Kristha Pertiwi Homeschooling, Semarang Regency, use bunchems in therapeutic activity [13]. The texture of the ball which underlies of its use to stimulate fine motor skills in hands area.

In this study, we present the effects of using bunchems to increase the fine motor skill of children with mental retardation and global developmental delay in Kristha Pertiwi Homeschooling, Semarang Regency.

\section{Method}

The subject in this study was a 7-year-olds with mental retardation and global developmental delay who difficulties in fine motor. Characteristics of fine motor skills were weak in grasping objects, limp when scooping objects, and irregular coordination when grazing objects.

This study used single case design research that accepted behavior analysis procedures for managing or modifying behavior. We used multiple design cross variables with two conditions $\mathrm{A}-\mathrm{B}$. A is a baseline condition that no treatment is given at all and $\mathrm{B}$ is an intervention condition through using bunchems. The purpose of behavior in this study is a child can grasping, grazing and scooping objects without falling from her hands.

At the baseline condition (A) we observed a child's fine motor skill in grasping objects for 7 days, grazing objects for 10 days, and scooping objects for 13 days. At the intervention condition (B) subject received treatment using bunchems for 11 days in grasping objects, 8 days in grazing objects, and 5 days in scooping objects. The observation lasted for one hour each day.

We recorded the frequency of expected behavior when children perform fine motor activities in the period to collect the data. Then, the data analyzed by describing the graphics display and the measurement of the fine motor skills of the child. Data analysis used visual analysis technique to differentiate conditions on graphed data by within-condition analysis and between-condition analysis. The steps of within-condition shown in Table 1 and the steps of between-condition analysis in the Table 2.

Table 1. Steps of Within-Condition Analysis

\begin{tabular}{ll}
\hline Components & Steps \\
\hline $\begin{array}{l}\text { Condition length } \\
\text { Estimate trend } \\
\text { Trend stability }\end{array}$ & $\begin{array}{l}\text { Count the number of sessions for each condition } \\
\text { Calculate trend using the split-middle method of trend estimation } \\
\text { Calculate the percent of data points within the stability envelope for each } \\
\text { condition }\end{array}$ \\
$\begin{array}{l}\text { Data paths within the } \\
\text { trend }\end{array}$ & $\begin{array}{l}\text { Use freehand method" to evaluate data paths } \\
\text { Stability of level } \\
\text { Level change }\end{array}$ \\
\hline
\end{tabular}


Table 2. Steps of Between-Conditions Analysis

\begin{tabular}{ll}
\hline Components & Steps \\
\hline Number of variables that changed & $\begin{array}{l}\text { Determine the number of variables that changed between } \\
\text { conditions } \\
\text { Identify trend direction across adjacent conditions }\end{array}$ \\
$\begin{array}{l}\text { Change in trend direction between } \\
\text { Change in trend stability }\end{array}$ & $\begin{array}{l}\text { Compare the decision from data paths within trend to the } \\
\text { number of sessions by the condition }\end{array}$ \\
$\begin{array}{l}\text { The level change between conditions } \\
\text { Overlap of data between conditions }\end{array}$ & \begin{tabular}{l} 
Calculate the percent of overlapping data \\
\hline
\end{tabular} \\
\hline
\end{tabular}

\section{Results and Discussion}

The observational data to the subjects is shown in the graph in Figure 1. The graph data shows the results obtained on the subject under the study for the fine motor skill of grasping, grazing and scooping objects.

Within-condition analysis of grasping performance shows stability level in baseline condition tends to equal on the number $1-3$, but in intervention condition up on the number 6 -8 . Estimate trend and data paths within the trend in baseline condition are equal $(=)$, but in the intervention, condition is up or positive $(+)$. Trend stability in baseline condition is stable at $100 \%$ and in intervention condition is stable at $96 \%$. Level change in baseline condition has not changed $(=)$ from $2-2$, but in intervention condition has positive $(+)$ changed from $5-8$.

Within-condition analysis of grazing performance shows stability level in baseline condition tends to down on the number $0-3$, but in intervention condition up on the number 6 -9 . Estimate trend and data paths within the trend in baseline condition are down or negative $(-)$, but in the intervention, condition is up or positive (+). Trend stability in baseline condition is variable at $80 \%$ and in intervention condition is stable at $88 \%$. Level change in baseline condition has negative (-) changed from $3-1$, but in the intervention condition has positive (+) changed from $8-9$.

Within-condition analysis of scooping performance shows stability level in baseline condition tends to equal on the number $0-3$, but in intervention condition up on the number 6 -7 . Estimate trend and data paths within the trend in baseline condition are equal $(=)$, but in the intervention, condition is up or positive $(+)$. Trend stability in baseline condition is stable at $85 \%$ and in intervention condition is stable at $100 \%$. Level change in baseline condition has no changed (=) from $2-2$, but in intervention condition has positive $(+)$ changed from $6-7$.

Between-condition analysis of grasping performance shows a change in trend direction between adjacent conditions have positive $(+)$ changed. Change in trend stability is from stable to stable. The level change between conditions tends to be positive (+) with 3 points from 2 to 5 . There $0 \%$ overlap of data between conditions.

Between-condition analysis of grazing performance shows a change in trend direction between adjacent conditions have positive $(+)$ changed. Change in trend stability is from variable to stable. The level change between conditions tends to be positive (+) with 7 points from 1 to 8 . There $0 \%$ overlap of data between conditions. 
Between-condition analysis of grazing performance shows a change in trend direction between adjacent conditions have positive $(+)$ changed. Change in trend stability is from stable to stable. The level change between conditions is tend to be positive (+) with 4 point from 2 to 6 . There $0 \%$ overlap of data between conditions.
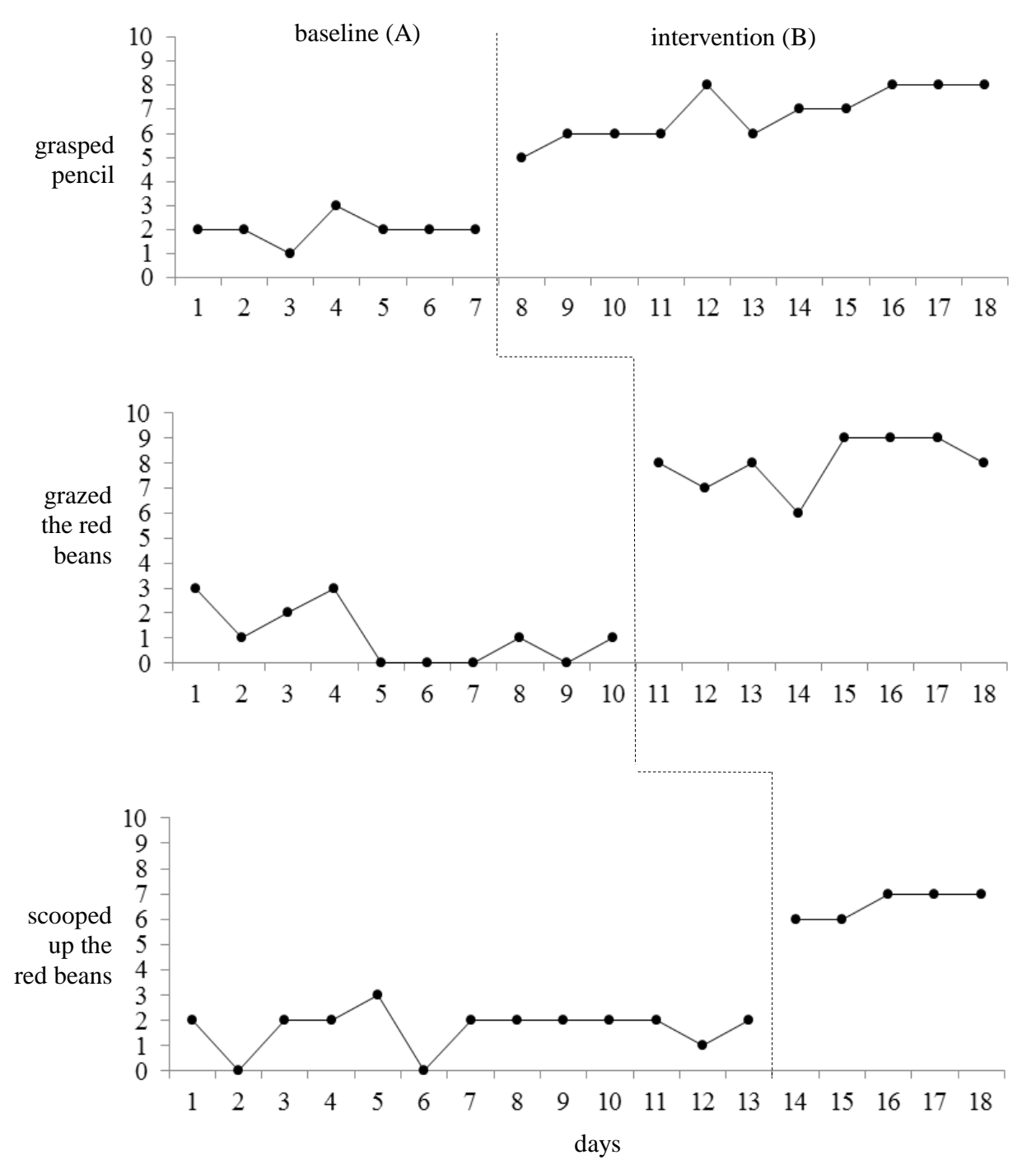

Fig. 1. Graphed Data of Multiple Design Cross Variables with Two Conditions (A-B) 
Table 3. Within-Condition Analysis

\begin{tabular}{|c|c|c|c|c|c|c|}
\hline \multirow{2}{*}{ Components } & \multicolumn{2}{|c|}{ Grasping } & \multicolumn{2}{|c|}{ Grazing } & \multicolumn{2}{|c|}{ Scooping } \\
\hline & A & B & A & B & A & B \\
\hline Condition length & 7 & 11 & 10 & 8 & 13 & 5 \\
\hline \multirow{2}{*}{ Estimate trend } & - & I & 1 & I & - & I \\
\hline & $(=)$ & $(+)$ & $(-)$ & $(+)$ & $(=)$ & $(+)$ \\
\hline \multirow{3}{*}{ Trend stability } & Stabl & stabl & variabl & stabl & stabl & stabl \\
\hline & e & $\mathrm{e}$ & $\mathrm{e}$ & $\mathrm{e}$ & $\mathrm{e}$ & $\mathrm{e}$ \\
\hline & $\begin{array}{c}100 \\
\%\end{array}$ & $91 \%$ & $80 \%$ & $88 \%$ & $85 \%$ & $\begin{array}{c}100 \\
\%\end{array}$ \\
\hline \multirow{2}{*}{$\begin{array}{l}\text { Data paths within } \\
\text { trend }\end{array}$} & - & I & 1 & I & - & I \\
\hline & $(=)$ & $(+)$ & $(-)$ & $(+)$ & $(=)$ & $(+)$ \\
\hline \multirow{3}{*}{ Stability of level } & $1-3$ & $6-8$ & $0-3$ & $6-9$ & $0-3$ & $6-7$ \\
\hline & Stabl & stabl & variabl & stabl & stabl & stabl \\
\hline & $\mathrm{e}$ & $\mathrm{e}$ & $\mathrm{e}$ & $\mathrm{e}$ & $\mathrm{e}$ & $\mathrm{e}$ \\
\hline \multirow{2}{*}{ Level change } & $2-2$ & $5-8$ & $3-1$ & $8-9$ & $2-2$ & $6-7$ \\
\hline & $(=0)$ & $(+3)$ & $(-2)$ & $(+1)$ & $(=0)$ & $(+1)$ \\
\hline
\end{tabular}

Table 4. Between-Condition Analysis

\begin{tabular}{|c|c|c|c|}
\hline Compared between conditions & $\begin{array}{c}\text { Grasping } \\
\text { B/A }\end{array}$ & $\begin{array}{c}\text { Grazing } \\
\text { B/A }\end{array}$ & $\begin{array}{c}\text { Scooping } \\
\text { B/A }\end{array}$ \\
\hline Numbers of variables that changed & 1 & 1 & 1 \\
\hline \multirow[t]{2}{*}{$\begin{array}{l}\text { Change in trend direction between } \\
\text { adjacent conditions }\end{array}$} & (=) & $\begin{array}{c}/ \\
(+)\end{array}$ & $\begin{array}{l}- \\
(=)\end{array}$ \\
\hline & \multirow{2}{*}{$\begin{array}{c}\text { Positive } \\
\text { stable to stable }\end{array}$} & \multirow{2}{*}{$\begin{array}{c}\text { positive } \\
\text { variable to stable }\end{array}$} & \multirow{2}{*}{$\begin{array}{c}\text { positive } \\
\text { stable to stable }\end{array}$} \\
\hline Change in trend stability & & & \\
\hline Level change between conditions & $\begin{array}{l}2-5 \\
(+3)\end{array}$ & $\begin{array}{l}1-8 \\
(+7)\end{array}$ & $\begin{array}{l}2-6 \\
(+4)\end{array}$ \\
\hline Overlap of data between conditions & $0 \%$ & $0 \%$ & $0 \%$ \\
\hline
\end{tabular}

After a measured grasping performance to the subject, we obtained the score before treatment $(\mathrm{A})$ is $1-3$. But, when we provided treatment through bunchems (B) the score is 5 8. The results of the within-condition analysis showed the trend from baseline condition to intervention condition has positive changed. Positive changed and low overlap percentage $(0 \%)$ between-condition showed the use of bunchems gave positive effect to fine motor skill, especially in grasping performance, which frequency increased. The highest frequency in intervention condition (B) began appeared on the twelfth days and stable from sixteenth to eighteenth days. We assumed on the eighth days the subject have tried to start adjusting with bunchems used for intervention. Nevertheless, the child gradually responded and continued to develop on the next days. However, the number had decreased on the thirteenth days and up again steadily until intervention is completed. 
Based on the preliminary observation, the grasping performance by the subject tends to be weak. The objects easily separated from her grasp because her grasp did not close perfectly. She had difficulty to grasping objects more than 15 seconds without fall from her hands. After the intervention through bunchems, the fingers and the palm of the child's hands felt the stimulus to learn to grasp with the strength of her fingers. The child tried to mobilize her strength to the objects gradually.

We obtained the score before treatment $(\mathrm{A})$ is $0-3$ when grazing performance. But, when we provided treatment through bunchems (B) the score is $6-9$. The results of the within-condition analysis showed the trend from baseline condition to intervention condition has positive changed. Positive changed and low overlap percentage $(0 \%)$ between-condition showed the use of bunchems gave positive effect to fine motor skill, especially in grazing performance, which frequency increased. The highest frequency in intervention condition (B) began appeared on the fifteenth days and stable to the next days. We assumed on the eleventh days the subject have tried to start adjusting with bunchems used for intervention. Nevertheless, the child gradually responded and continued to develop on the next days. However, the number had decreased on the fourteenth days and up again steadily until intervention is completed.

The grazing performance by the subject tends to be irregular coordination of her forefinger and thumb. The objects easily separated from her graze because her fingers did not narrow objects strongly. She also had difficulty in grazing objects more than 15 seconds without fall from her fingers. After the intervention through bunchems, the fingers of the child's hands felt the stimulus to learn to graze with the strength of her fingers. The child tried to mobilize her finger's strength to the objects gradually.

The score before treatment (A) is $0-3$ when scooping performance. But, when we provided treatment through bunchems (B) the score is $6-7$. The results of the withincondition analysis showed the trend from baseline condition to intervention condition has positive changed. Positive changed and low overlap percentage $(0 \%)$ between-condition showed the use of bunchems gave positive effect to fine motor skill, especially in scooping performance, which frequency increased. The highest frequency in intervention condition (B) began appeared on the sixteenth days and stable to the next days. The child gradually responded and continued to develop on the next days.

The scooping performance by the subject tends to be limp. The objects easily separated from her fingers because her fingers did not close perfectly to keep the object in it. She had difficulty to scooping objects more than 5 seconds without fall from her hand. After the intervention through bunchems, the fingers of the child's hands felt the stimulus to learn with the strength of her fingers. The child tried to mobilize her finger's strength to the scoop up the objects as much as possible gradually.

\section{Conclusion}

Used of bunchems increased the fine motor skill of child with mental retardation and global developmental delay by grasping, grazing, and scooping performance. The child gradually responded to the stimulus and learn to develop her fine motor skills while intervention condition. The effect of intervention become increase and stable. 
Acknowledgements. We are grateful to the teachers in Kristha Pertiwi Homeschooling, Semarang Regency for the opportunity to complete this study to their student.

\section{References}

[1]Thomas, R. (1977). The effects of knowledge of results upon motor skill performance of the trainable mentally retarded. Dissertation Abstracts International, 10-A.

[2]Wells, K. (2006). Fine Motor Skills. The Gale Encyclopedia of Children's Health: Infancy through Adolescence, 2, 756-760.

[3]Huffman, J., \& Fortenberry, C. (2011). Helping Preschoolers Prepare in Writing: Developing Fine Motor Skills. Youn Children, 100-103.

[4Linwood, A. (2006). Developmental Delay. The Gale Encyclopedia of Children's Health: Infancy through Adolescence, 2, 593-597.

[5]Schalock, R., Luckasson, R., Shogren , K., Borthwick-Duffy, S., Bradley, V., \& Buntinx, W. (2007). The Renaming of Mental Retardation: Understanding the Change to the Term Intellectual Disability. Intellectual and Developmental Disabilities, 45, 116-124.

[6]Zikl, P., Holoubková, N., Karásková, H., \& Veselíková, T. (2013). Gross Motor Skills of Children with Mild Intellectual Disabilities. World Acad Sci Eng Technol Int J Soc Behav Educ Econ Manage Eng, 7, 2789-95.

[7]Beirne-Smith, M., Patton, J., \& Kim, S. (2006). Mental Retardation. New Jersey: Pearson.

[8]Bouffard, M. (1990). Movements Problem Solutions by Educable Mentally Handicapped Individuals. Adapted Physical Quarterly, 7, 183-197.

[9]Rarick, G. (1973). Motor Performance of Mentally Retarded Children. Physical Activity: Human Growth and Development, 22-256.

[10]Piaget, J., \& Inhelder, B. (1966). La Psychologie De L'enfant. Paris: Presses Universitaires de France.

[11]Wassenberg, R., Kessels, A., Kalff, A., Hurks, P., Jolles, J., \& Feron, F. (2005). Relation between cognitive and motor performance in 5- to 6-year-old children: results from a large-scale crosssectional study. Child Development, 76, 1092-1103.

[12]Diamond, A. (2000). Close Interrelation of Motor Development and Cognitive Development and of the Cerebellum and Prefrontal Cortex. Child Development, 71, 44-56.

[13]Spin-Master. (n.d.). Squish 'em! Connect 'em! Create 'em! Retrieved from Bunchems: http://www.bunchems.com/index.php?loc=en_US. 